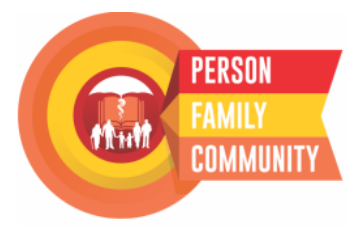

Journal Homepage:

https://jurnal.ugm.ac.id/rpcpe
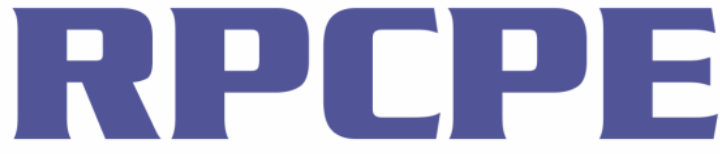

ISSN 2613-943X (print) ISSN 2620-5572 (online) (Kajian Praktik dan Pendidikan Layanan Primer)

\title{
Prediabetes Screening with American Diabetes Association (ADA) Scoring in the Primary Health Care Yogyakarta
}

\author{
Yaltafit Abror Jeem ${ }^{1}$, Hari Koesnanto ${ }^{2}$, M. Robikhul Ikhsan ${ }^{3}$ \\ ${ }^{1}$ Clinical Medicine; Department of Family and Community Medicine; Faculty of Medicine, Public Health, and Nursing; \\ Universitas Gadjah Mada; Indonesia \\ ${ }^{2}$ Department of Family and Community Medicine; Faculty of Medicine, Public Health, and Nursing; Universitas Gadjah Mada \\ Indonesia \\ 3 Department of Internal Medicine, Diabetic Endocrine Sub Part; Faculty of Medicine, Public Health, and Nursing; Universitas \\ Gadjah Mada; Indonesia
}

Corresponding Author:

Yaltafit Abror Jeem: Clinical Medicine; Department of Family and Community Medicine; Faculty of Medicine, Public Health, and Nursing; Universitas Gadjah Mada, J1. Farmako, Senolowo, Sekip Utara, Sleman, Daerah Istimewa Yogyakarta - 55281, Indonesia E-mail: dr.yaltafit.a.j@gmail.com

To cite this article:

Jeem YA, Koesnanto H, Ikhsan MR. Prediabetes screening with american diabetes association (ADA) scoring in the Primary Health Care Yogyakarta. Rev Prim Care Prac and Educ. 2020; 3(2): 22-26.

\begin{abstract}
Background: Numerous studies have shown an increase in prediabetes incidence from the time being. Some of the prediabetes screening methods that can be performed at primary health care were the American Diabetes Association (ADA) scoring for prediabetes. However, there was no data that describes the validity and applicability of the ADA scoring on prediabetes patients in Indonesia. Objective: To describe prediabetes screening and to find out the applicability of the ADA scoring method in Yogyakarta primary health care. Method: The diagnostic test by the scoring system of the ADA questionnaire was compared with OGTT (oral glucose tolerance test) as the gold standard. The subjects were patients of primary health care in Yogyakarta who fulfill the inclusion and exclusion criteria. Result: The subjects were 279 respondents with 227 females (81.4\%) and 52 male patients (18.6\%). The mean age of the study subjects was 50.4 years (SD 12.81). The sensitivity and specificity of the scoring method of ADA was $61 \%$ and $71 \%$. This could be influenced by the difference in BMI standard as one of the scoring items. After some item scoring points were modified, namely gender point value and BMI classification, the sensitivity of the scoring method was higher, from $61 \%$ to $81 \%$ and the specificity decreased from $71 \%$ to $63 \%$. Conclusion: Prediabetes prevalence was $11.1 \%$ in the study population. The sensitivity and specificity of the scoring method of ADA is $61 \%$ and $71 \%$. The scoring method of ADA could not be used in primary health care.
\end{abstract}

Keywords: ADA, primary health care, prediabetes, risk factor scoring, screening

\section{INTRODUCTION}

Numerous studies have shown an increasing incidence rate and prevalence of prediabetes over time. More than 470 million people estimated will experience prediabetes by $2030^{1}$. Prediabetes prevalence in Southeast Asia is estimated at $6.8 \%^{2}$. The research of Suwondo and Pramono shows that the prevalence of prediabetes (GDPT) in Indonesia is $10 \%{ }^{3}$. This prevalence is estimated to increase to $20.6 \%$ by $2025^{2}$. The highest prevalence of prediabetes was 38-47 years old at $25.8 \%$, and at age $\geq 58$ years was $21.9 \%^{3}$.

Based on baseline health research data in 2013 the prevalence of DM in Yogyakarta Special Region (DIY) is $2.6 \%$ and is the highest prevalence of DM in Indonesia followed by DKI Jakarta with $2.5 \%$ and North Sulawesi $2.4 \%{ }^{4}$. Prediabetes prevalence rates in DIY are not yet known. Prediabetes prevalence in DKI Jakarta is $24.91 \%$ at 25-64 years old ${ }^{5}$. While the prevalence of prediabetes in Depok Java was $24.25 \%$ at age $\geq 25$ years $^{6}$. Screening should be done because the majority of people with prediabetes are unaware of the risk of diabetes ${ }^{7}$. The annual risk of prediabetes patients to type 2 diabetes is 5$10 \%$. Some people with prediabetes also reported complications both microvascular and macrovascular ${ }^{10}$. Waught, Scotland, Gillet, Brennan, Goyder, Williams, and John stated screening in patients with prediabetes could prevent complications significantly in cardiovascular disease $^{11}$. Zhang, Engelgau, Valdez, Benjamin, Cadwell, and Narayan use the cost analysis method to assess the efficacy (sensitivity and specificity) and cost-effectiveness of five prediabetes diagnostic and screening methods ${ }^{12}$.

It has been found from these studies that TTGO has been the most efficient way. While capillary glucose testing and questionnaire scoring for risk assessment are the most effective methods. Patients prefer fasting blood glucose tests compared to TTGO. Other prediabetes screening trials were conducted using scoring techniques. Poltavskiy, Kim, and Bang compared both ADA and CDC screening results. The findings of the ADA scoring are comparatively better. AUC (Area Under Curve) ADA scores for DM are 0.77 and CDC 
scores for prediabetes are AUC 0.73-0.74 and AUC 0.720.74 and $\mathrm{CDC}$ for prediabetes are $0.70-0.71^{13}$.

A systematic review by Norris, Kansagara, Bougatsos, and $\mathrm{Fu}$ shows that screening of high-risk groups at primary health facilities can also reduce the progression from prediabetes to diabetes ${ }^{14}$. This can be reduced due to previous interventions in pre-diabetes patients, such as lifestyle changes and pharmacological therapy. Besides, studies on dietary modification show that prediabetes converts to normal glucose tolerance or normoglycemia ${ }^{15}$. Prediabetes is one of the health problems that must be detected and intervened earlier in primary health facilities. One way is through screening. Research on screening for prediabetes in Indonesia has not been done much. Screening with ADA scoring is one of the methods that is often used and has a good and effective level of accuracy in several countries. The use of this method has not been widely used in Indonesia, especially in primary services. Therefore, this research needs to be carried out which can describe effective and efficient screening methods for prediabetes at primary health facilities. So, how a description of a prediabetes screening at DIY primary health care facilities using the ADA scoring method?

\section{RESEARCH METHOD}

This type of research is an analytic observational study. The approach taken is based on the diagnostic test of the ADA Prediabetes Test Scoring System compared to TTGO as the gold standard. All patients $\geq 25$ years of age in primary health care facilities at DIY were in the study population. The selection of the sample is performed by cluster sampling. The inclusion criteria for this study are as follows: age $\geq 25$ 85 years, willing to follow research with informed consent, able to communicate well. Although the exclusion criteria are as follows: diagnosed with DM, diagnosed with gestational DM. The study was performed in April-May 2017. This research was conducted in April-May 2017. The study was conducted in three primary health care facilities in Yogyakarta. Respondents were recruited by health cadres in the community. Respondents go through 2 processes before becoming a respondent. The first stage of the respondent filled out questions related to the history and status of DM and treatment. The second stage of the respondent followed the examination of capillary glucose checks and the results of fasting venous blood glucose.

This instrument comes from the ADA Prediabetes Screening Test ${ }_{13}$. This questionnaire will first be translated into Indonesian by an official translation body and then tested for validity and reliability. If the result score is 0-3, then the patient is declared to have a low risk of prediabetes if the total score is $\geq 4$, then the patient is interpreted as a patient who is currently at high risk of having prediabetes, and is at high risk for having diabetes in the future. Data processing, statistical analysis, and hypothesis testing were carried out with the SPSS 2.

\section{RESULTS}

The study was conducted in two regencies in DIY, namely two primary health care center working areas in the Sleman regency and one Bantul regency working area, Puskesmas Tempel, PuskesmasKalasan, and Puskesmas Kasihan I. A total of 346 respondents was willing to become research samples after being given an informed consent explanation. However, as many as 67 people were excluded from the study because 18 patients had a history of DM from the results of history taking and 59 patients were diagnosed with DM from fasting blood sugar and blood sugar based on glucose meter.

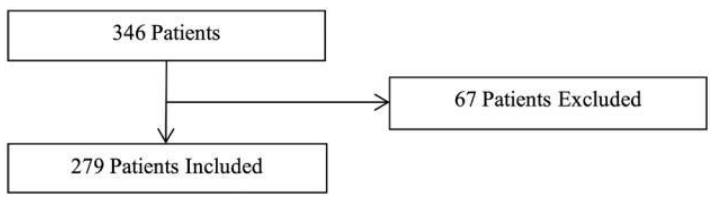

\section{Diagram 1. Enrolment patient}

A total of 279 respondents with 227 female respondents $(81.4 \%)$ and 52 male respondents $(18.6 \%)$. The average age was 50.4 years (SD 12.81). The average weight and height of the respondents was $58.3 \mathrm{~kg}$ (SD 11.4) and $152.6 \mathrm{~cm}$ (SD 7.41). As many as $47 \%$ (131 respondents) were included in the normal (BMI 18.5-24.99 $\mathrm{kg} / \mathrm{m}_{2}$ ). However, $35.8 \%$ were included in the pre-obesity/overweight ratio (BMI 25.00$29.99 \mathrm{~kg} / \mathrm{m} 2$ ). The mean abdominal circumference for all respondents was $86.1 \mathrm{~cm}$. The prevalence of prediabetes in this study was $11 \%$ (31 out of 279 subjects).

The method used in this study was a questionnaire based on the ADA. The questionnaire was translated into Indonesian by the Faculty of Cultural Sciences Translation Department of the Gadjah Mada University and tested for validity and reliability. The questionnaire was distributed to 30 respondents and the results were analyzed. The validation test used in this study is Pearson's bivariate correlation (Pearson product-moment). The bivariate Pearson correlation test results obtained by each question item have a value of $r$ greater than the $\mathrm{r}$ table ( $\mathrm{r}$ : 0.306). Pearson bivariate correlation test criteria on is if $r$ arithmetic $>r$ table (2-sided test with sig. 0.05), then the instrument or question items are significantly correlated with the total score (declared valid). Meanwhile, if, on the contrary, it has been declared invalid. Therefore, all questions in the questionnaire are valid from the results of the validity test.

From the $2 \times 2$ table calculation, the sensitivity of the ADA score method is $61 \%$, which means that $61 \%$ of prediabetes patients are categorized as having a high risk of prediabetes at present based on the ADA score method. The specificity of the ADA score method is 71 percent, which means that 71 percent of healthy subjects are currently categorized as not at high risk of prediabetes based on the ADA score method.

Table 2. Table diagnostic test scoring method of ADA

\begin{tabular}{|c|c|c|c|}
\hline \multirow{2}{*}{$\begin{array}{c}\text { Scoring System of } \\
\text { ADA }\end{array}$} & \multicolumn{2}{|c|}{ Prediabetes } & \multirow[t]{2}{*}{ Total } \\
\hline & Yes & No & \\
\hline Prediabetes & 19 & 72 & 91 \\
\hline Normal & 12 & 176 & 188 \\
\hline Total & 31 & 248 & 279 \\
\hline
\end{tabular}

The positive predictive value of this scoring method is $21 \%$, meaning that the probability of subjects suffering from prediabetes if categorized as having prediabetes by 
Table 1. Characteristics of the research subject

\begin{tabular}{|c|c|c|}
\hline Characteristic & Frequency & Percentage* \\
\hline \multicolumn{3}{|l|}{ Gender } \\
\hline Female & 227 & $81.4 \%$ \\
\hline Male & 52 & $18.6 \%$ \\
\hline \multicolumn{3}{|l|}{ Age } \\
\hline Mean and SD & 50.4 years old (SD 12.81) & \\
\hline Minimum and Maximum & 25 and 84 years old & \\
\hline \multicolumn{3}{|l|}{ Classification Age } \\
\hline$<40$ years & 66 & $23.7 \%$ \\
\hline $40-49$ years & 61 & $21.9 \%$ \\
\hline $50-59$ years & 85 & $30.5 \%$ \\
\hline$\geq 60$ years & 67 & $24.0 \%$ \\
\hline \multicolumn{3}{|l|}{ Weight } \\
\hline Mean and SD & $58.3 \mathrm{~kg}(\mathrm{SD} 11.4)$ & \\
\hline \multicolumn{3}{|l|}{ Height } \\
\hline Mean and SD & $152.6 \mathrm{~cm}(\mathrm{SD} 7.41)$ & \\
\hline \multicolumn{3}{|l|}{ Body Mass Index (BMI) } \\
\hline Underweight & 15 & $5.4 \%$ \\
\hline Normal weight & 132 & $47.3 \%$ \\
\hline Pre-Obese & 100 & $35.8 \%$ \\
\hline Obesity Class I & 25 & $9.0 \%$ \\
\hline Obesity Class II & 5 & $1.8 \%$ \\
\hline Obesity Class III & 2 & $0.7 \%$ \\
\hline Mean and SD BMI & $25.6 \mathrm{~kg} / \mathrm{m}^{2}(\mathrm{SD} 10.6)$ & \\
\hline \multicolumn{3}{|l|}{ Gestational DM History } \\
\hline No & 276 & $98.9 \%$ \\
\hline \multicolumn{3}{|l|}{ Family History of DM } \\
\hline No & 191 & $68.5 \%$ \\
\hline Yes & 88 & $31.5 \%$ \\
\hline \multicolumn{3}{|l|}{ Hypertension } \\
\hline No & 177 & $63.4 \%$ \\
\hline Yes & 102 & $36.6 \%$ \\
\hline \multicolumn{3}{|c|}{ Physical Activity based on Questionnaire } \\
\hline Yes & 279 & $100 \%$ \\
\hline \multicolumn{3}{|l|}{ Scoring ADA } \\
\hline Mean and SD & $2.75(\mathrm{SD} 1.68)$ & \\
\hline Minimum & 0 & \\
\hline Maximum & 7 & \\
\hline \multicolumn{3}{|c|}{ Prediabetes Scoring based on ADA } \\
\hline Normal $\quad($ score $0-3)$ & 188 & $67.4 \%$ \\
\hline Prediabetes (score 4-11) & 91 & $32.6 \%$ \\
\hline \multicolumn{3}{|c|}{ Prediabetes Scoring by ADA with Modifications*** } \\
\hline Normal $\quad($ score $0-3)$ & 162 & $58 \%$ \\
\hline Prediabetes (score 4-11) & 117 & $42 \%$ \\
\hline \multicolumn{3}{|l|}{ Prediabetes based on OGTT } \\
\hline Normal & 248 & $88.9 \%$ \\
\hline Prediabetes & 31 & $11.1 \%$ \\
\hline
\end{tabular}

the ADA scoring method is $21 \%$. The negative predictive value is 94 percent, meaning that the probability of the subject not suffering from prediabetes if the test is categorized as not having the risk of prediabetes by the ADA scoring method is 94 percent. The positive likelihood ratio $(\mathrm{LR}+)$ is 2.11 , which means a comparison between the numbers of patients who have prediabetes risk at present with the ADA scoring method in the prediabetes group compared to patients who have prediabetes risk with the ADA scoring method in the healthy subject group. The positive predictive value of this scoring method is $21 \%$, meaning that the probability of subjects suffering from prediabetes if categorized as having prediabetes by the ADA scoring method is $21 \%$. The negative predictive value is $94 \%$, meaning that the probability of the subject not suffering from prediabetes if the test is categorized as not having the risk of prediabetes by the ADA scoring method is $94 \%$. The positive likelihood ratio $(\mathrm{LR}+)$ is 2.11 , which means a comparison between the number of patients who have prediabetes risk at present with the ADA scoring method in the prediabetes group compared to patients who have prediabetes risk with the ADA scoring method in the healthy subject group. A negative likelihood ratio (LR-) of 0.55 means a comparison between patients who do not have the current risk of prediabetes in the prediabetes group compared to those who do not have a prediabetes risk with the current ADA scoring method in the healthy subject group. The accuracy or accuracy of the ADA scoring method is $69.8 \%$. 
Tabel 3. Table diagnostic test scoring method of ADA with modification

\begin{tabular}{lccc}
\hline \multirow{2}{*}{$\begin{array}{c}\text { Scoring System of } \\
\text { ADA }\end{array}$} & \multicolumn{2}{c}{ Prediabetes } & Total \\
\cline { 2 - 4 } & Yes & No & \\
\hline Prediabetes & 25 & 92 & 117 \\
Normal & 6 & 156 & 162 \\
Total & 31 & 248 & 279
\end{tabular}

Sn: 81\%; PPV: 21\%; Sp: 63\%; NPV: 96\%; LR+:2.17;

LR-:0.31; Accuration $=64.8 \%$

The sensitivity value is quite low as a screening tool, it becomes an opportunity to change values or points on several scoring items and be simulated in this research data. After some item scoring points were modified, namely gender point value and BMI classification, the sensitivity of the scoring method was higher, from $61 \%$ to $81 \%$ and the specificity decreased from $71 \%$ to $63 \%$. The positive forecast value of this scoring method is $21 \%$ remains the same. The negative predictive value is higher, from $94 \%$ to $96 \%$. Positive Likelihood Ratio ( $\mathrm{LR}+$ ) is higher from
2.11 to 2.17 . While the Negative Likelihood Ratio (LR-) decreased from 0.55 to 0.31 . The accuracy or accuracy of the ADA scoring method decreased from $69.8 \%$ to $64.8 \%$.

\section{DISCUSSION}

The prevalence of prediabetes at the age of 25-85 years in DIY based on the data of this study is $11.1 \%$. This is not much different from the results of Soewondo and Pramono's research which is $10 \%^{3}$. Meanwhile, according to IDF (International Diabetes Federation) data, the prevalence of prediabetes in Southeast Asia is estimated to be around 6.8\% (lower $4.2 \%)^{2}$. This might occur due to differences in the demographic characteristics of the research subjects. Yunir's study states that the prevalence of prediabetes at the age of 25-64 years in DKI Jakarta is $24.91 \%{ }^{5}$. Besides, the prevalence of prediabetes in Depok West Java is also not much different is $24.25 \%$ at the age of 25 years old ${ }^{6}$. This is different from the results of this study because of differences in demographic characteristics of research subjects such as the age range, gender proportion, and the possibility of socioeconomic and cultural factors.

Table 4. Differences method of scoring ADA

\begin{tabular}{|c|c|c|}
\hline Item Question & Original Version & Modified Version \\
\hline 1. Age Category & $\begin{array}{l}<40 \text { years old }(0 \text { point }) \\
40-49 \text { years old ( } 1 \text { point }) \\
50-59 \text { years old }(2 \text { points }) \\
>60 \text { years old }(3 \text { points })\end{array}$ & Not Modified \\
\hline 2. Gender & $\begin{array}{l}\text { Male (1 point) } \\
\text { Female ( } 0 \text { point })\end{array}$ & $\begin{array}{l}\text { Male }(0 \text { point }) * \\
\text { Female (1 point) }\end{array}$ \\
\hline 3. Family History of DM & $\begin{array}{l}\text { Yes }(1 \text { point }) \\
\text { No }(0 \text { point })\end{array}$ & Not Modified \\
\hline 4. Hypertension & $\begin{array}{l}\text { Yes ( } 1 \text { point }) \\
\text { No }(0 \text { point })\end{array}$ & Not Modified \\
\hline 5. Physical Activity & $\begin{array}{l}\text { Yes ( } 0 \text { point }) \\
\text { No ( } 1 \text { point })\end{array}$ & Not Modified \\
\hline 6. Weight Status & $\begin{array}{l}<27.5 \mathrm{~kg} / \mathrm{m}^{2}(0 \text { point }) \\
27.5-32.49 \mathrm{~kg} / \mathrm{m}^{2}(1 \text { point }) \\
32.50-44.00 \mathrm{~kg} / \mathrm{m}^{2}(2 \text { points }) \\
\geq 44.00 \mathrm{~kg} / \mathrm{m}^{2}(3 \text { points })\end{array}$ & $\begin{array}{l}<25.0 \mathrm{~kg} / \mathrm{m}^{2}(0 \text { point }) * \\
25.0-27.49 \mathrm{~kg} / \mathrm{m}^{2}(1 \text { point }) \\
27.50-32.49 \mathrm{~kg} / \mathrm{m}^{2}(2 \text { point }) \\
\geq 32.50 \mathrm{~kg} / \mathrm{m}^{2}(3 \text { point })\end{array}$ \\
\hline
\end{tabular}

From the $2 \times 2$ table calculation, the sensitivity and specificity of the ADA scoring method (with a score $\geq 4$ ) were $61 \%$ and $71 \%$. This is different from the results of Bang, Edwards, Bomback, Ballantyne, Brillon, Callahan, Teutsch, Mushlin, and Kern research which found that the sensitivity and specificity of the ADA scoring method (with a score of $\geq 4$ ) is $76 \%$ and $54 \%^{16}$. Besides, in the study of Poltavsky, et al., It was also found that the sensitivity and specificity of the ADA scoring method for the ADA scoring method (with a score $\geq$ 4) were $73 \%$ and $57 \%{ }^{13}$. Differences in sensitivity and specificity values are possible due to differences in the demographic characteristics of the study subjects including the mean BMI (25.6 kg/m2: $\left.28.2 \mathrm{~kg} / \mathrm{m}_{2}: 28.3 \mathrm{~kg} / \mathrm{m}_{2}\right)$ and the proportion of sex $(1: 4$ and $1: 1$ and $1: 1)$ which results in low sensitivity and specificity of ADA scoring in the study population. WHO Expert Consultations concluded that the cut off of BMI at risk of diabetes and heart disease in Asian populations is lower than the cut-off of WHO overweight (25 $\left.\mathrm{kg} / \mathrm{m}_{2}\right)^{17}$. Correspondingly, Hsia, Larrivee, Cefalu, and Johnson recommend that the IMT cut-off for prediabetes screening be lower $\left(\geq 23 \mathrm{~kg} / \mathrm{m}_{2}: \geq 25 \mathrm{~kg} / \mathrm{m}_{2}\right)$ in Asian populations and increase the sensitivity of prediabetes screening in populations aged $\geq 45$ years $^{18}$. This is due to the high percentage of body fat and abdominal circumference in Asian populations compared to European populations ${ }^{19}$. Therefore, some item points from the ADA scoring system were modified i.e. the point values of the sex items were exchanged and the IMT classification was based on the WHO obesity criteria for the Asia Pacific population, the sensitivity value of the scoring method was higher, from $61 \%$ to $81 \%$ but the specificity value dropped from $71 \%$ to $63 \%$.

Based on the $2 \times 2$ table analysis results, the positive predictive value, and negative predictive value of this scoring method is $21 \%$ and $94 \%$. This is different from the results of research by Bang, et al., found that the positive predictive value and negative predictive value of the ADA scoring method is $50 \%$ and $78 \%{ }^{16}$. Correspondingly, in the study of Poltavsky, et al., It was found that the positive predictive value and the negative predictive value of the ADA scoring method were $53 \%$ and $77 \%{ }^{13}$. This difference is possible due to differences in some of the demographic characteristics of the subjects including the proportion of sex and the mean and the proportion of BMI. In this study the proportion of male sex is not balanced which is $1: 4(81.4 \%: 18.6 \%)$ different from the 
study of Bang, et al., and Poltavsky, et al., which is $1: 1^{16,13}$. As a screening tool, a fairly low sensitivity value $(61 \%)$ makes this scoring method an opportunity to be modified and simulated by changing points based on the respondent's context or characteristics. After some of the items scoring points have been modified, namely gender point value and BMI classification, the positive predictive value remains the same but the negative predictive value is higher ie from $94 \%$ to $96 \%$. As for the accuracy value of the ADA scoring method based on the research of Bang, et al., and Poltavsky, et al., namely $73 \%$ and $79 \% 16,13$. In this study, the accuracy or accuracy of the ADA scoring method is $69.8 \%$. After the points and items of gender and obesity criteria were modified to drop to $64.8 \%$. The limitation of this study is that the proportion of sexes that is not balanced has an impact on the inference of the results of research in other populations. But this can be reduced by the analysis of gender adjustment. No other factor was measured as a question item in the scoring method questionnaire such as central obesity, smoking status, and cholesterol levels ${ }^{20,21,3}$. The strength of this study is that the ADA scoring method was found with the modification that is sensitive and quite specific in screening patients with prediabetes and can be used in primary health facilities.

\section{CONCLUSIONS}

The ADA scoring method cannot be used directly at primary level health facilities. The sensitivity and specificity of the ADA scoring method are $61 \%$ and $71 \%$. The ADA scoring method with relative modification can be used at primary level health facilities. After some points of the item scoring are modified, the sensitivity and specificity of the scoring method become $81 \%$ and $63 \%$.

\section{Acknowledgments}

Thanks to all medical nurses, all medical analysts for helping this research and clinical pathology laboratory of FKKMK UGM.

\section{Ethical Approval and Informed Consent}

This research has been approved by the Medical and Health Research Ethics Committee (MHREC) from the Faculty of Medicine, Public Health, and Nursing, Universitas Gadjah Mada with reference number KE/FK/0672/EC/2017.

\section{Funding}

Self-funding.

\section{Availability of Data and Material}

Data and material can be accessed via the corresponding author.

\section{Conflict of Interest}

None.

\section{REFERENCES}

1. Tabák AG, Herder C, Rathmann W, Brunner EJ, Kivimäki M. Prediabetes: a high-risk state for diabetes development. The Lancet. 2012; 379(9833): 2279-90.
2. International Diabetes Federation. IDF Diabetes Atlas sixth edition. 2013. Available at: www.idf.org/diabetesatlas.

3. Soewondo P, Pramono LA. Prevalence, characteristics, and predictors of pre-diabetes in Indonesia. Medical Journal of Indonesia. 2011; 20(4): 283-94.

4. Agency for Health Research and Development. Basic Health Research 2013. Jakarta: Ministry of Health Republic of Indonesia; 2013.

5. Yunir E. Presentation of the results of internal medicine research: the prevalence of pre-diabetes in the general population aged 25-64 years in five regions of DKI Jakarta. 2013.

6. Yunir E, Waspadji S, Rahajeng E. The pre-diabetic epidemiological study in Depok, West Java. Acta Med Indones. 2009; 41(4): 181-5.

7. Serrano R, García-Soidán FJ, Diaz-Redondo A, Artola S, Franch J, Diez J, Carrillo L, Ezkurra P, Millaruelo JM, Segui M, Sangrós FJ. Cohort study in primary health care on the evolution of patients with prediabetes (PREDAPS): basis and methodology. Revista espanola de salud publica. 2013; 87(2): 121-35.

8. Gerstein HC, Santaguida P, Raina P, Morrison KM, Balion C, Hunt D, Yazdi H, Booker L. Annual incidence and relative risk of diabetes in people with various categories of dysglycemia: a systematic overview and meta-analysis of prospective studies. Diabetes Research and Clinical Practice. 2007; 78(3): 305-12.

9. Nathan DM, Davidson MB, DeFronzo RA, Heine RJ, Henry RR, Pratley R, Zinman B. Impaired fasting glucose and impaired glucose tolerance: implications for care. Diabetes Care. 2007; 30(3): 753-9.

10. Rydén L, Standl E, Bartnik M, Van den Berghe G, Betteridge J, De Boer MJ, Cosentino F, Jönsson B, Laakso M, Malmberg K, Priori S. Guidelines on diabetes, pre-diabetes, and cardiovascular diseases: executive summary: The Task Force on Diabetes and Cardiovascular Diseases of the European Society of Cardiology (ESC) and of the European Association for the Study of Diabetes (EASD). European Heart Journal. 2007; 28(1): 88-136.

11. Waugh N, Scotland G, Gillet M, Brennan A, Goyder E, Williams R, John A. Screening for type 2 diabetes: literature review and economic modelling. Health Technology Assessment. 2007; 11(17): 1-143.

12. Zhang P, Engelgau MM, Valdez R, Benjamin SM, Cadwell B, Narayan KV. Costs of screening for pre-diabetes among US adults: a comparison of different screening strategies. Diabetes Care. 2003; 26(9): 2536-42.

13. Poltavskiy E, Kim DJ, Bang H. Comparison of screening scores for diabetes and prediabetes. Diabetes Research and Clinical Practice. 2016; 118: 146-53.

14. Norris SL, Kansagara D, Bougatsos C, Fu R. Screening adults for type 2 diabetes: a review of the evidence for the US Preventive Services Task Force. Annals of Internal Medicine. 2008; 148(11): 855-68.

15. Stentz FB, Brewer A, Wan J, Garber C, Daniels B, Sands C, Kitabchi AE. Remission of pre-diabetes to normal glucose tolerance in obese adults with high protein versus high carbohydrate diet: a randomized control trial. BMJ Open Diabetes Research and Care. 2016; 4(1): 1-9.

16. Bang H, Edwards AM, Bomback AS, Ballantyne CM, Brillon D, Callahan MA, Teutsch SM, Mushlin AI, Kern LM. Development and validation of a patient self-assessment score for diabetes risk. Annals of Internal Medicine. 2009; 151(11): 775-83.

17. WHO Expert Consultation. Appropriate body-mass index for Asian populations and its implications for policy and intervention strategies. Lancet (London, England). 2004; 363(9403): 157.

18. Hsia DS, Larrivee S, Cefalu WT, Johnson WD. Impact of lowering BMI cut points as recommended in the revised American Diabetes Association's Standards of Medical Care in Diabetes-2015 on diabetes screening in Asian Americans. Diabetes Care. 2015; 38(11): 2166-8.

19. Zeng Q, He Y, Dong S, Zhao X, Chen Z, Song Z, Chang G, Yang F, Wang Y. Optimal cut-off values of BMI, waist circumference and waist: height ratio for defining obesity in Chinese adults. British Journal of Nutrition. 2014; 112(10): 1735-44.

20. Ouyang P, Guo X, Shen Y, Lu N, Ma C. A simple score model to assess prediabetes risk status based on the medical examination data. Canadian Journal of Diabetes. 2016; 40(5): 419-23.

21. Hutabarat YHN. Central obesity as a risk factor for prediabetes in Cimahi City [Ph.D Thesis]. Yogyakarta: Universitas Gadjah Mada; 2012. 